\title{
Kepatuhan dan Kualitas Hidup Pasien Diabetes Melitus Tipe 2 di Rumah Sakit di Jawa Tengah
}

\section{Adherence and Quality of Life Patients of Diabetes Melitus Type 2 in Hospitals in Central Java}

\author{
Nurul Mutmainah*, Muhammad Al Ayubi, Anggie Widagdo \\ Fakultas Farmasi Universitas Muhammadiyah Surakarta \\ J1. Ahmad Yani, Tomol Pos 1, Pabelan Kartasura Surakarta 57102 Telp. (0271) 717417 \\ *E-mail: Nurul.mutmainah@ums.ac.id
}

Received: 10 Oktober 2020; Accepted: 28 Desember 2020; Published: 31 Desember 2020

\begin{abstract}
Abstrak
Diabetes melitus adalah salah satu penyakit kronis yang membutuhkan pengobatan dalam jangka waktu yang panjang. Kepatuhan mengkonsumsi obat menjadi salah satu hal terpenting dalam mencapai tujuan pengobatan. Penelitian ini bertujuan untuk mengetahui tingkat kepatuhan dan kualitas hidup serta mengetahui pengaruh kepatuhan terhadap kualitas hidup pasien DM tipe 2 di rumah sakit di Jawa Tengah. Penelitian ini menggunakan desain analitik dengan pendekatan cross-sectional. Sampel diambil di dua rumah sakit di Jawa Tengah. Pengambilan sampel secara purposive sampling dengan kriteria pasien diabetes mellitus tipe 2 yang menjalani rawat jalan di rumah sakit, telah menjalani terapi minimal 3 bulan, dan dapat berkomunikasi dengan baik. Sebagai alat ukur kepatuhan digunakan kuesioner Medication Adherence Rating Scale (MARS) sedangkan alat ukur kualitas hidup digunakan kuesioner Short Form 36 (SF-36). Data skor kepatuhan dan kualitas hidup yang telah didapatkan akan diolah dengan program SPSS (Statistical Product and Service Solutions) uji chi-square. Hasil penelitan pada 200 responden ditemukan 9 orang $(4,5 \%)$ memiliki kepatuhan rendah, 46 orang $(23 \%)$ kepatuhan sedang dan 145 orang (72,5\%) memiliki kepatuhan tinggi. Sedangkan kualitas hidup ditemukan 41 orang $(20,5 \%)$ memiliki kualitas hidup yang buruk dan 159 orang $(79,5 \%)$ memiliki kualitas hidup yang baik. Aspek kualitas hidup yang paling rendah adalah keterbatasan fisik dan aspek kualitas hidup yang paling tinggi adalah kesehatan mental. Dari hasil analisis pada uji chi square diperoleh nilai $p$ value: 0,00. Hal ini menunjukkan adanya hubungan yang signifikan antara kepatuhan dan kualitas hidup pada pasien diabetes mellitus Tipe2 di rumah sakit tersebut dan nilai Prevalensi Rasio sebesar 23,47
\end{abstract}

Kata Kunci: Kepatuhan, kualitas hidup, diabetes mellitus tipe 2, MARS, SF36

\begin{abstract}
Diabetes mellitus is a chronic disease that requires treatment for a long period of time. Adherence to consuming drugs is one of the most important things in achieving treatment goals. This study aims to determine the level of adherence and quality of life and determine the relationship to the quality of life of patients with type 2 DM in hospitals in Central Java. This study uses analytic design by asking cross-sectional. Samples were taken at two hospitals in Central Java. Sampling was purposive sampling with the criteria of type 2 diabetes mellitus patients who are undergoing outpatient care in the hospital, have undergone therapy for at least 3 months, and can communicate well. As a measurement used the Medication Adherence Rating Scale (MARS) questionnaire while the quality of life measure used the Short Form 36 (SF-36) questionnaire. Score data received and quality of life that has been obtained was processed with the SPSS (Product Statistics and Service Solutions) chi-square test. Research results in 200 respondents found 9 people (4.5\%) had low adherence, 46 people (23\%) were moderately related and 145 people (72.5\%) have high adherence. While the quality of life found 41 people (20.5\%) had a poor quality of life and 159 people (79.5\%) had a good quality of life. The lowest aspect of quality of life is physical limitations and the highest aspect of quality of life is mental health. From the results of the analysis on the chi square test, the p value was obtained: 0.00. This shows that there is a significant relationship between adherence and quality of life in patients with Type 2 diabetes mellitus at the hospitals and a Prevalence Ratio value of 23.47 .
\end{abstract}

Keywords: Adherence, Quality of Life, Type 2 Diabetes Mellitus, MARS, SF36. 


\section{PENDAHULUAN}

Diabetes Melitus (DM) merupakan penyakit yang terjadi akibat produksi insulin yang tidak efektif sehingga menggangu keseimbangan gula di dalam tubuh. Diabetes mellitus tipe 2 disebabkan oleh insulin di dalam tubuh yang kurang stabil .presentase penderita diabetes melitus tipe 2 mencapai 90\% dari penderita diabetes melitus yang ada (Depkes RI,2014). Menurut survey Kesehatan Rumah Tangga (SKRT) tahun 2001 penderita DM pada usia 25- 64 tahun, $7,5 \%$ di Jawa dan Bali. Jumlah kasus penderita DM tipe 2 pada usia 25-64 tahun sebesar $12,8 \%$ dan $11,2 \%$ pada tahun 2003 setelah dilakukannya penanggulangan terhadap pasien (Depkes RI, 2008). Terdapat beberapa penyebab terjadinya ketidakpatuhan antara lain masalah ekonomi, efek samping obat dan sulit dalam mengelola obat. Ketidakpatuhan menyebabkan meningkatnya risiko komplikasi penyakit kronis seperti neuropati,retinopati,dan penyakit ginjal. (Miller dan Di Matteo ,2013). Komplikasi dapat dicegah dengan mengendalikan kadar gula dalam darah dengan berbagai kegiatan non farmakologis maupun farmakologis. Diabetes melitus juga menjadi penyakit yang tidak dapat disembuhkan yang menyebabkan pengelolaan dan perawatan yang tepat menjadi sangat penting agar kualitas hidup pasien terpelihara dengan baik.

Berdasarkan penelitian yang dilakukan oleh Hasina et al. (2014) tentang hubungan tingkat kepatuhan, kepuasan terapi dengan kualitas hidup pasien usia lanjut diabetes melitus tipe 2 disimpulkan dari seluruh pasien diabetes melitus tipe 2 usia lanjut di RSUP Dr.SardjitoYogyakarta dikategori patuh $(81,7 \%)$, puas $(7,10 \pm 1,05)$, hasil yang diperoleh yaitu terdapat hubungan yang signifikan antara kepatuhan dan kualitas hidup ( $\mathrm{p}=0,012)$, dan tidak ada hubungan yang signifikan antara kepuasan terapi dengan kualitas hidup ( $\mathrm{p}=0,089$ ). Hasil penelitian menggunakan uji chi square tersebut menunjukkan bahwa adanya hubungan yang bermakna $(\mathrm{p}<0,05)$ antara kepatuhan dengan kualitas hidup responden. Hal ini dapat menjelaskan bahwa semakin tinggi kepatuhan maka akan menghasilkan kualitas hidup yang semakin baik. Untuk itu perlu dilakukan penelitian dengan tujuan untuk mengetahui tingkat kepatuhan dan kualitas hidup serta mengetahui hubungan kepatuhan terhadap kualitas hidup pasien DM tipe 2 di rumah sakit di Jawa Tengah dengan responden semua umur pasien.

\section{METODE PENELITIAN}

Penelitian ini menggunakan desain analitik dengan pendekatan cross-sectional. Dalam penelitian ini sebagai variabel bebas adalah tingkat kepatuhan pasien sedangkan variabel tergantung dalam penelitian ini adalah kualitas hidup pasien. Alat ukur variabel digunakan kuesioner kepatuhan minum obat Medication Adherence Rating Scale (MARS) dan kuesioner Kualitas Hidup Short Form 36 (SF-36).

Populasi penelitian ini adalah semua pasien DM tipe 2 rawat jalan di rumah sakit di Jawa Tengah. Sampel diambil dari dua rumah sakit di Jawa Tengah dan sampel yang telah memenuhi kriteria inklusi yang dikumpulkan dengan teknik purposive sampling.

Kriteria Inklusi dari penelitian ini adalah 1) Pasien DM Tipe 2 yang menjalani rawat jalan, 2)Telah menjalani terapi minimal 3 bulan, 3) Dapat berkomunikasi verbal dengan baik, 4) Bersedia menjadi responden.

Besar sampel yang dibutuhkan berdasarkan rumus perkiraan besaran sampel menurut penelitian analitik cross-sectional :

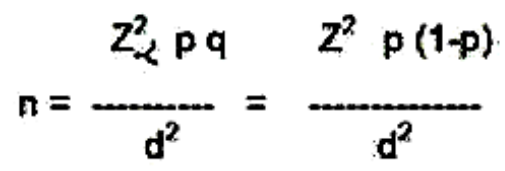

Di mana $\mathrm{n}$ adalah besar sampel minimum, $\mathrm{z}$ adalah nilai $\mathrm{z}$ pada derajat kepercayaan $(1,96), \mathrm{P}$ adalah proporsi pada kelompok yang sudah diketahui $(0,5)$, dan $\mathrm{d}$ adalah presisi mutlak (10\%). 


$$
\mathrm{n}=\left(1,96^{2} \times 0,5 \times 0,5\right) / 0,1^{2}=96,04
$$

Berdasarkan rumus di atas, maka besar sampel yang dibutuhkan dapat dibulatkan menjadi 100 sampel tiap rumah sakit.

Berdasarkan penelitian Rachmawati dan Perwitasari (2014) yang menguji validitas kuesioner Short form-36 (SF-36) dari 30 pasien dengan menggunakan uji validitas konvergen dan deskriminan yang semua item pertanyaan menghasilkan nilai $\geq 0,4$ sehingga dinyatakan valid dan hasil uji reliabilitas dengan uji statistika cronbach's alpha dinyatakan sudah reliabel dengan semua domain menghasilkan nilai $\geq 0,7$.

Berdasarkan penelitian Alfian dan Putra (2017) yang menguji validitas kuesioner MARS dengan uji korelasi Pearson, pertanyaan kuisioner dinyatakan valid apabila nilai $\mathrm{R}$ hitung lebih besar dari $\mathrm{R}$ Tabel. Nilai $R$ untuk 25 pasien adalah 0,396 dan $\mathrm{R}$ hitung dari semua pertanyaan menunjukan nilai yang lebih besar, maka semua pertanyaan dinyatakan sudah valid. Uji statistika cronbach's alpha untuk menilai reliabilitas dan hasil menunjukan semua pertanyaan sudah sudah reliable karena didapatkan nilai $\geq 0,70$.

Jenis data yang digunakan yaitu data primer, data yang langsung dikumpulkan oleh peneliti. Teknik pengumpulan data menggunakan teknik wawancara dengan instrumen yaitu kuesioner kualitas hidup yang diadopsi dari short form-36 (SF-36) dan kuesioner kepatuhan pasien yang diadopsi dari Medication Adherence Rating Scale (MARS).

Medication Adherence Rating Scale (MARS) merupakan instrumen yang digunakan untuk mengukur tingkat kepatuhan pasien diabetes melitus tipe 2 di dua RS di Jawa Tengah yang dihitung berdasarkan 5 pertanyaan dari kuesioner MARS dengan interpretasi sebagai berikut (Naafi dkk., 2016):
a. Skor $0-5=$ Kepatuhan rendah
b. Skor 6-24=Kepatuhan sedang
c. Skor $25=$ Kepatuhan tinggi

Short Form-36(SF-36) merupakan instrumen yang dipilih untuk menilai tingkat kualitas hidup pasien diabetes melitus tipe2 di rumah sakit di Jawa tengah yang terdiri dari 36 pertanyaan yang terbagi dalam 8 aspek yaitu nyeri tubuh, keterbatasan fisik, fungsi fisik, kesehatan mental, vitalitas, fungsi sosial, keterbatasan emosional, dan kesehatan secara umum yang diinterpretasikan sebagai berikut (Ningrum dkk.,2016):

a. skor $\angle 50=$ Kualitas hidup buruk

b. skor $\geq 50=$ Kualitas hidup baik

Data yang sudah diperoleh kemudian dianalisis dengan software SPSS (Statistical product and Service Solution) sebagai berikut:

1. Analisis univariat. Analisis ini akan mendiskripsikan masing-masing variabel dengan menghitung frekuensi dan presentase hasil analisis numerik maupun kategorik.

2. Analisis bivariat. Analisis ini akan menjelaskan hubungan antara kepatuhan dan kualitas hidup dengan menggunakan uji chi-square. Apabila didapatkan $p$ value $<0,05$ bisa diartikan bahwa kepatuhan bisa mempengaruhi kualitas hidup pasien DM tipe 2 di rumah sakit di Jawa Tengah.

Penelitian ini telah mendapat persetujuan Komite Etik Penelitian FK UMS No.1907.2019 dan No.1908.2019.

\section{HASIL DAN PEMBAHASAN Karakteristik Pasien}

Dari data rekam medik diperoleh sampel yang memenuhi kriteria inklusi sebanyak 200 pasien dengan karakteristik ditunjukkan pada Tabel 1. Berdasarkan Tabel 1 nampak bahwa responden pasien diabetes melitus tipe 2 paling banyak ditemukan pada usia lansia akhir (56-65 tahun). Umur merupakan salah satu faktor risiko yang dapat meningkatkan angka kejadian diabetes melitus. Umur berkaitan dengan kadar glukosa di dalam darah yang tinggi, sehingga semakin bertambahnya umur akan meningkatkan gangguan toleransi glukosa. Proses bertambahnya umur yang berlangsung lebih 
Tabel 1. Karakteristik pasien diabetes melitus tipe 2 di rumah sakit di Jawa Tengah tahun 2019

\begin{tabular}{|c|c|c|}
\hline Karakteristik & Frekuensi (f) & Persentase (\%) $\mathrm{N}=200$ \\
\hline \multicolumn{3}{|l|}{ Umur } \\
\hline Dewasa Awal (21-35) & 7 & 3,5 \\
\hline Dewasa Akhir (36-45) & 13 & 6,5 \\
\hline Lansia Awal (46-55) & 40 & 20 \\
\hline Lansia Akhir (56-65) & 87 & 43,5 \\
\hline Masa Manula (>65) & 53 & 26,5 \\
\hline \multicolumn{3}{|l|}{ Jenis Kelamin } \\
\hline Laki-Laki & 84 & 42 \\
\hline Perempuan & 116 & 58 \\
\hline \multicolumn{3}{|l|}{ Pekerjaan } \\
\hline Tdk bekerja/IRT & 89 & 44,5 \\
\hline Petani & 12 & 6 \\
\hline Swasta & 21 & 10,5 \\
\hline PNS & 33 & 16,5 \\
\hline Pensiunan & 45 & 22,5 \\
\hline \multicolumn{3}{|l|}{ Lama Menderita DM } \\
\hline 3 bulan -1 tahun & 11 & 5,5 \\
\hline 1-5 tahun & 20 & 10 \\
\hline$>5$ tahun & 169 & 84,5 \\
\hline \multicolumn{3}{|l|}{ Status } \\
\hline Menikah & 197 & 98,5 \\
\hline Belum Menikah & 3 & 1,5 \\
\hline
\end{tabular}

dari 30 tahun dapat berakibat anatomis, fisiologis, dan biokimia berubah (Felicia, 2017). Menurut WHO, umur lebih dari 30 tahun kadar glukosa akan bertambah 1$2 \mathrm{mg} / \mathrm{dl} /$ tahun saat puasa dan bertambah 5,6$13 \mathrm{mg} / \mathrm{dl}$ pada 2 jam sesudah makan (Felicia,2017).

Menurut jenis kelamin responden pasien diabetes melitus tipe 2 didapatkan pasien perempuan sebanyak 58\%. Berdasarkan prevalensi kejadian DM tipe 2 pada perempuan lebih tinggi daripada laki-laki karena secara fisik wanita mempunyai peluang bertambahnya indeks masa tubuh yang lebih besar. Sindroma siklus bulanan (premenstrual syndrome), pascamenopouse yang dapat membuat distribusi lemak didalam tubuh menjadi mudah terakumulasi akibat adanya proses hormonal tersebut mengakibatkan perempuan lebih berisiko menderita diabetes melitus tipe 2
(Irawan, 2010 dalam Setyorogo dan Trisnawati,2013).

Berdasarkan lama menderita didapatkan untuk status lama menderita $>5$ tahun adalah paling banyak. Hal ini terkait dengan komplikasi pada pasien diabetes melitus tipe 2 yang juga berkaitan dengan kualitas hidupnya.

\section{Karakteristik Obat}

Sebanyak 200 sampel pasien mendapatkan pengobatan yang bervariasi tergantung pada masing-masing kondisi pasien, hal ini tercantum dalam Tabel 2. Pada Tabel 2 nampak bahwa obat yang paling banyak digunakan adalah monoterapi obat glimepirid (16,5\%) dan terapi kombinasi yang sering digunakan adalah metformin dan glimeperid (12,5\%), sedangkan terapi insulin yang sering digunakan ialah novorapid yang dikombinasikan dengan lantus (11\%). Menurut Perkeni (2015) penggunaan obat 
Tabel 2. Profil penggunaan obat antihiperglikemia yang diresepkan kepada pasien diabetes mellitus tipe2 di rumah sakit di Jawa Tengah tahun 2019

\begin{tabular}{|c|c|c|c|}
\hline & Nama obat & Jumlah & $\operatorname{Persentase}(n=200)$ \\
\hline \multirow[t]{7}{*}{ Tunggal } & Glimepiride & 33 & 16,5 \\
\hline & Metformin & 23 & 11,5 \\
\hline & Novorapid & 9 & 4,5 \\
\hline & Gliclazide & 8 & 4 \\
\hline & Lantus & 2 & 1 \\
\hline & Gliquidone & 1 & 0,5 \\
\hline & Acarbose & 1 & 0,5 \\
\hline \multirow[t]{21}{*}{ Kombinasi 2 obat } & Glimepiride+Metformin & 25 & 12,5 \\
\hline & Novorapid+Lantus & 12 & 6 \\
\hline & Acarbose+Gliclazid & 9 & 4,5 \\
\hline & Gliclazide+Metformin & 9 & 4,5 \\
\hline & Novorapid+Metformin & 6 & 3 \\
\hline & Novorapid+Levemir & 5 & 2,5 \\
\hline & Lantus+Gliclazide & 4 & 2 \\
\hline & Lantus+Metformin & 2 & 1 \\
\hline & Lantus+Gliquidone & 2 & 1 \\
\hline & Metformin+Gliquidone & 2 & 1 \\
\hline & Lantus+Apidra & 2 & 1 \\
\hline & Glimepiride+Levemir & 2 & 1 \\
\hline & Acarbose+Metformin & 2 & 1 \\
\hline & Acarbose+Glimepiride & 2 & 1 \\
\hline & Acarbose+Pioglitazone & 1 & 0,5 \\
\hline & Gliclazide+Pioglitazone & 1 & 0,5 \\
\hline & Levemir+Pioglitazone & 1 & 0,5 \\
\hline & Novorapid+Glicazid & 1 & 0,5 \\
\hline & Novorapid+Glimepirid & 1 & 0,5 \\
\hline & Levemir+Gliclazide & 1 & 0,5 \\
\hline & Levemir+Metformin & 1 & 0,5 \\
\hline \multirow[t]{12}{*}{ Kombinasi 3 obat } & Acarbose+Metformin+Gliclazide & 7 & 3,5 \\
\hline & Novorapid+Metformin+Gliclazid & 5 & 2,5 \\
\hline & Lantus+Gliclazide & 4 & 2 \\
\hline & Acarbose+Metformin+Lantus & 3 & 1,5 \\
\hline & Acarbose+Metformin+Glimepiride & 2 & 1 \\
\hline & Lantus+Gliclazide+Metformin & 2 & 1 \\
\hline & Acarbose+Gliclazide+Pioglitazone & 1 & 0,5 \\
\hline & Acarbose+Glimepiride+Pioglitazone & 1 & 0,5 \\
\hline & Metformin+Pioglitazone+Gliclazide & 1 & 0,5 \\
\hline & Glimepiride+Metformin+Gliclazide & 1 & 0,5 \\
\hline & Lantus+Metformin+Glimeperid & 1 & 0,5 \\
\hline & Levemir+Metformin+Gliclazid & 1 & 0,5 \\
\hline \multirow[t]{4}{*}{ Kombinasi 4 obat } & Acarbose+Glimepiride+Metformin+Pioglitazone & 2 & 1 \\
\hline & Acarbose+Metformin+Apidra+Lantus & 1 & 0,5 \\
\hline & Acarbose+Metformin+Novorapid+Levemir & 1 & 0,5 \\
\hline & Acarbose+Gliclazide+Pioglitazone+Levemir & 1 & 0,5 \\
\hline
\end{tabular}

hipoglikemia kombinasi lebih dianjurkan daripada meningkatkan dosis satu macam obat hipoglikemia yang dapat meningkatkan risiko toksisitas dan efek samping. Dua atau lebih obat hipoglikemia dengan mekanisme aksi yang berbeda bila digunakan secara bersama dapat memberikan manfaat yang lebih baik dalam mengontrol kadar glukosa darah. 
Tabel 3. Profil penyakit komplikasi pasien diabetes melitus tipe 2 di rumah sakit di Jawa Tengah tahun 2019

\begin{tabular}{lcc}
\hline Komplikasi penyakit & Frekuensi & Persentase N = 200 \\
\hline Tanpa Komplikasi & 61 & 30,5 \\
Hipertensi & 58 & 29 \\
Hipertensi + Dispepsia/gastritis & 15 & 7,5 \\
Ulkus diabetikum & 14 & 7 \\
IHD & 9 & 4,5 \\
Hipertensi + Asma + Pneumonia & 8 & 4 \\
Hipertensi + Ulkus diabetikum & 7 & 3,5 \\
Hipertensi + gagal jantung & 6 & 3 \\
RA & 5 & 2,5 \\
Hipertensi + Asma & 4 & 2 \\
Hipertensi + OA & 2 & 1 \\
Stroke & 2 & 1 \\
Hiperglikemi & 2 & 1 \\
Gastritis & 2 & 1 \\
Hipertensi + HNP + Alzheimer & 1 & 0,5 \\
Hipertensi + BPH + Dispepsia +OA & 1 & 0,5 \\
PPOK & 1 & 0,5 \\
CHF & 1 & 0,5 \\
Ulkus diabetikum + Encelopati uremikum & 1 & 0,5 \\
\hline
\end{tabular}

Pada Tabel 3 nampak profil penyakit komplikasi yang paling banyak diderita pasien diabetes melitus tipe 2 di rumah sakit di Jawa Tengah pada tahun 2019 adalah hipertensi (38\%). Hal ini dapat disebabkan karena penyebaran usia penderita lebih banyak pada usia lansia akhir (56-65 tahun), persentase penyakit tidak menular kronis dapat meningkat karena adanya proses penuaan (Rosyada dan Trihandini, 2013). Selain itu hipertensi juga menjadi faktor risiko timbulnya penyakit diabetes melitus tipe 2 (PERKENI,2015). Pada diabetes mellitus selain keadaan hiperglikemia/ gangguan toleransi glukosa sebagai factor risiko juga dapat ditemukan factor risiko lain seperti resistensi insulin, hyperinsulinemia, dislipidemia, hipertensi, hiperkoagulasi, obesitas visceral, mikroalbuminuria. Keadaan yang sangat multifactorial ini menyebabkan insidensi penyakit kardiovaskuler pada diabetes tinggi. Dasar patofisiologi dari kelainan tersebut adalah adanya gangguan pada metabolism (abnormality metabolism) yang disebut sindroma metabolic. Hubungan sindroma metabolic dengan factor risiko penyakit kardiovaskuler adalah terjadinya proses atherosclerosis yang menggambarkan terjadinya disfungsi endotel.(Permana, 2009)

\section{Kepatuhan Pasien}

Tingkat kepatuhan adalah penilaian terhadap pasien untuk mengetahui apakah pasien tersebut telah mengikuti aturan penggunaan obat dalam menjalani terapi. Kepatuhan konsumsi obat pasien diabetes melitus dapat menjadi pertimbangan terkait pemilihan jenis terapi. Berdasarkan hasil penelitian Rasdianah dkk.(2016) ketidakpatuhan pasien dapat ditimbulkan karena beberapa hal seperti aktivitas pekerjaan yang padat akibat kesibukan bekerja, kelupaan minum obat karena beberapa alasan, biaya obat yang terasa memberatkan bagi pasien. Hasil penelitian kepatuhan pasien diabetes melitus tipe 2 di RS di Jawa Tengah tahun 2019 tercantum pada Tabel 4.

Berdasarkan tingkat kepatuhan pasien diabetes mellitus tipe 2 di RS di Jawa Tengah menunjukkan sebagian besar $(72,5 \%)$ pasien memiliki tingkat kepatuhan yang tinggi terhadap obat yang telah diberikan. 
Tabel 4. Data Kepatuhan pasien diabetes melitus tipe 2 di rumah sakit di Jawa Tengah Tahun 2019

\begin{tabular}{ccc}
\hline Kepatuhan & Frekuensi & Persentase (\%) $\mathbf{N}=\mathbf{2 0 0}$ \\
\hline Rendah & 9 & 4,5 \\
Sedang & 46 & 23 \\
Tinggi & 145 & 72,5 \\
\hline
\end{tabular}

Tabel 5. Data Pasien Kualitas Hidup diabetes melitus tipe 2 di rumah sakit di Jawa Tengah Tahun

\begin{tabular}{ccc} 
& $\mathbf{2 0 1 9}$ & \\
\hline Kualitas Hidup & Frekuensi(f) & Persentase (\%) $\mathbf{N = 2 0 0}$ \\
\hline Buruk & 41 & 20,5 \\
Baik & 159 & 79,5 \\
Jumlah & 200 & 100 \\
\hline
\end{tabular}

Tabel 6. Deskripsi penilaian kualitas hidup DM tipe 2 di rumah sakit di Jawa Tengah tahun 2019 berdasarkan 8 aspek dari kuesioner SF-36

\begin{tabular}{cc}
\hline Aspek & Skor Rata-rata \\
\hline Kesehatan mental & 83,75 \\
Fungsi sosial & 74,85 \\
Fungsi fisik & 75,00 \\
Nyeri tubuh & 65,61 \\
Vitalitas & 65,78 \\
Kesehatan secara umum & 57,73 \\
Keterbatasan emosional & 54,32 \\
Keterbatasan fisik & 52.79 \\
\hline
\end{tabular}

\section{Kualitas Hidup}

Hasil penelitian kualitas hidup pada pasien diabetes melitus tipe 2 di rumah sakit di Jawa Tengah tercantum pada Tabel 5.

Berdasarkan Tabel 5 menunjukkan bahwa pasien diabetes melitus tipe 2 di rumah sakit di Jawa Tengah tahun 2019 sebagian besar $(79,5 \%)$ telah memiliki kualitas hidup yang baik. Kualitas hidup dapat ditinjau dari konteks budaya dan sistem nilai darimana mereka tinggal, serta berhubungan dengan standar hidup, harapan, kesenangan dan perhatian. Meningkatkan kualitas hidup diperlukan kerja keras dan konsistensi yang tinggi pada pasien diabetes melitus. Suatu individu dinyatakan memiliki kualitas hidup yang baik apabila memiliki kesehatan secara fisik, psikologis, dan mampu melakukan aktifitasnya seharihari. Selain itu umur juga dapat mempengaruhi fisik dan psikologis,bertambahnya umur dapat mempengaruhi penurunan fungsi organ sehingga dapat mempengaruhi kualitas hidup seseorang. Menjaga pola hidup juga dapat mempertahan kualitas hidup yang baik (Felicia,2017). Berdasarkan Tabel 6 menunjukkan skor rata-rata nilai dari keterbatasan fisik yang berupa masalahmasalah dalam pekerjaan atau aktifitas sehari-hari menjadi yang terendah hal ini berhubungan dengan faktor usia yang dialami pasien diabetes melitus tipe 2 di rumah sakit di Jawa Tengah dimana kebanyakan $(43,5 \%)$ berusia lansia akhir (Tabel 1). Salah satu cara untuk mempertahankan kondisi fisik yaitu dengan menjalani gaya hidup sehat yang menjadi salah satu terapi penting bagi pasien diabetes mellitus tipe 2 .

\section{Hubungan Antara Kepatuhan Dan Kualitas Hidup}

Hubungan kepatuhan dan kualitas hidup pasien diabetes melitus dilakukan dengan interpretasi hasil uji korelasi kepatuhan dengan kualitas hidup menggunakan uji chisquare dengan tingkat pemaknaan $p<0,05$ tercantum pada Tabel 7.

Dari hasil analisis didapatkan nilai $\mathrm{p}=0,000$ artinya ada hubungan yang signifikan antara kepatuhan dengan kualitas 
Tabel 7. Hubungan kepatuhan terhadap kualitas hidup pasien DM tipe 2 di rumah sakit di Jawa

\begin{tabular}{|c|c|c|c|c|c|c|c|}
\hline \multirow{3}{*}{ Kepatuhan } & \multicolumn{4}{|c|}{ KualitasHidup } & \multirow{2}{*}{\multicolumn{2}{|c|}{ Total }} & \multirow{3}{*}{$\begin{array}{c}\mathrm{P} \\
\text { Value }\end{array}$} \\
\hline & \multicolumn{2}{|c|}{ Buruk } & \multicolumn{2}{|c|}{ Baik } & & & \\
\hline & $\mathrm{F}$ & $\%$ & $\mathrm{~F}$ & $\%$ & $\mathrm{f}$ & $\%$ & \\
\hline Rendah dan Sedang & 31 & 56,4 & 24 & 43,6 & 55 & 100 & 0,000 \\
\hline Tinggi & 10 & 6,9 & 135 & 93,1 & 145 & 100 & \\
\hline Total & 41 & 20,5 & 159 & 79,5 & 200 & 100 & \\
\hline
\end{tabular}

hidup penderita diabetes melitus tipe 2 pada responden di rumah sakit tersebut. Hasil analisa diperoleh prevalence ratio $(P R)=$ 17,44 artinya pasien yang tingkat kepatuhannya tinggi memiliki prevalensi kualitas hidupnya baik sebesar 17,44 kali dibanding pasien yang tingkat kepatuhannya rendah. Hal ini berkaitan dengan kepatuhan penggunaan obat yang dapat mempengaruhi risiko komplikasi dan bertambah parahnya penyakit yang diderita yang secara langsung dapat mempengaruhi kualitas hidup pasien (Dewi dkk., 2018)

Salah satu tujuan akhir dari terapi diabetes melitus adalah meningkatnya taraf kualitas hidup yang merupakan pendapat kehidupan seseorang terhadap beberapa aspek kehidupan seperti aspek psikologis, biologis spiritual, lingkungan dan kemampuan seseorang dalam menjalankan fungsi kehidupannya (World Health Organization, 2016). Perubahan perilaku atau sikap pada pasien diabetes melitus juga diperlukan untuk mencapai salah satu tujuan terapi lainnya yaitu kadar gula yang terkontrol. Tujuan-tujuan tersebut tidak akan tercapai apabila tanpa disertai dengan kesadaran pasien terhadap pentingnya kepatuhan menjalani terapi. Berdasarkan dari uraian di atas, kepatuhan menjadi sangat penting terhadap kualitas hidup penderita diabetes mellitus tipe 2, selain itu pola hidup sehat harus dilakukan secara berimbang. Oleh karena itu seorang farmasis memiliki peran penting dalam meningkatkan kepatuhan penggunaan obat pada pasien melalui komunikasi, informasi, dan edukasi dengan tujuan meningkatkan kualitas hidup pasien.

\section{KESIMPULAN}

Hasil penelitan pada 200 responden pasien DM Tipe 2 di rumah sakit di Jawa Tengah ditemukan bahwa pasien dengan tingkat kepatuhan rendah sebanyak 9 orang $(4,5 \%)$, kepatuhan sedang 46 orang $(23 \%)$ dan kepatuhan tinggi 145 orang $(72,5 \%)$. Pasien dengan kualitas hidup buruk sebanyak 41 orang $(20,5 \%)$, kualitas hidup baik 159 orang $(79,5 \%)$. Aspek kualitas hidup yang paling rendah adalah keterbatasan fisik dan aspek kualitas hidup yang paling tinggi adalah kesehatan mental. Ditemukan adanya hubungan yang signifikan antara kepatuhan dan kualitas hidup pada pasien diabetes mellitus Tipe2 di rumah sakit tersebut dan nilai Prevalensi Rasio sebesar 17,44.

\section{Daftar Pustaka}

Alfian R. and Putra A.M.P., 2017, Uji Validitas dan Reliabilitas Kuesioner Medication Adherence Report Scale (MARS) Terhadap Pasien Diabetes Melitus, Jurnal ilmiah Ibnu Sina, 2 (September), 176-183.

Depkes RI., 2014, Situasi dan Analisis Diabetes, Jakarta

Dewi N.A., Susanto Y. and Wahyudi B., 2018, Kepatuhan Minum Obat dan Kualitas Hidup 
Pasien Diabetes Melitus di Depo BPJS Rawat Jalan RSUD Ulin Banjarmasin, Karya Tulis Ilmiah (KTI), Akademi Farmasi ISFI Banjarmasin.

Felicia, 2017, Hubungan antara depresi dengan kualitas hidup pada pasien diabetes melitus tipe 2 di Puskesmas Amplas Medan, Skripsi, Universitas Sumatera Utara. http://repositori.usu.ac.id/handle/123456789/4820

Hasina R., Probosuseno, Wiedyaningsih,C.,2014, Hubungan tingkat kepatuhan dan kepuasan terapi dengan kualitas hidup pasien usia lanjut diabetes mellitus tipe 2 di klinik Geriatri RSUP dr Sardjito Yogyakarta, Jurnal Manajemen dan Pelayanan Farmasi (Journal of Management and Pharmacy Practice, 4(4). 251-256.

Miller T.A. and Di Matteo M.R., 2013, Importance Of Family/Social Support and Impact on Adherence To Diabetic Therapy. Dovepress Journal, 6, 421-426.

Naafi A.M., Perwitasari D.A. and Darmawan E., 2016, Kepatuhan Minum Obat Pasien Rawat Jalan Skizofrenia Di Rumah Sakit Jiwa Prof.Dr.Soerojo Magelang, Kartika Jurnal Ilmiah Farmasi, 4 (2), 7-12.

Ningrum W.A.C., Hidayati T. and Rahmah, 2016, Kualitas Hidup Pasien Urolithiasis pada Komponen Fisik dan Komponen Mental dengan Instrumen Short Form-36 (SF-36), Jurnal Care, 4 (2), 53-63.

Perkumpulan Endokrinologi Indonesia, 2015, Konsensus Pengelolaan dan Pencegahan

Diabetes Melitus Tipe 2 di Indonesia 2015, PERKENI, Indonesia

Permana,H,,2009, Pengelolaan Hipertensi pada Diabetes Mellitus Tipe 2, . http://pustaka.unpad.ac.id/wp-

content/uploads/2009/09/pengelolaan_hipertensi_pada_diabetes_mellitus_tipe_2.pdf

Rachmawati Y., Perwitasari D.A. and Adnan, 2014, Validasi Kuesioner SF-36 Versi Indonesia Terhadap Pasien Hipertensi Di Puskesmas Yogyakarta, Jurnal Farmasi Indonesia, 11 (01), 14-25.

Rasdianah N., Martodiharjo S., Andayani T.M. and Hakim L., 2016, The Description of Medication Adherence for Patients of Diabetes Mellitus Type 2 in Public Health Center Yogyakarta, Indonesian Journal of Clinical Pharmacy, 5 (4), 249-257.

Setyorogo S. and Trisnawati S.., 2013, Faktor Risiko Kejadian Diabetes Melitus Tipe II Di Puskesmas Kecamatan Cengkareng Jakarta Barat Tahun 2012, Jurnal Ilmiah Kesehatan, 5 (1), 6-11.

World Health Organization, 2016, Global Tuberculosis Report, Law, I., ed., WHO Library Cataloguing-in-Publication Data, Geneva, Swtzerland. 